\title{
The control of an uncharted pinning point on the flow of an Antarctic ice shelf
}

\section{SOPHIE BERGER, ${ }^{1}$ LIONEL FAVIER,${ }^{1}$ REINHARD DREWS, ${ }^{1}$ JEAN-JACQUES DERWAEL, ${ }^{2}$ FRANK PATTYN ${ }^{1}$}

\author{
${ }^{1}$ Laboratoire de Glaciologie, Université libre de Bruxelles, Brussels, Belgium \\ ${ }^{2}$ Faculty of Applied Engineering, University of Antwerp, Antwerp, Belgium \\ Correspondence: Sophie Berger <sberger@ulb.ac.be>
}

\begin{abstract}
Antarctic ice shelves are buttressed by numerous pinning points attaching to the otherwise freely-floating ice from below. Some of these kilometric-scale grounded features are unresolved in Antarctic-wide datasets of ice thickness and bathymetry, hampering ice flow models to fully capture dynamics at the grounding line and upstream. We investigate the role of an $8.7 \mathrm{~km}^{2}$ pinning point at the front of the Roi Baudouin Ice Shelf, East Antarctica. Using ERS interferometry and ALOS-PALSAR speckle tracking, we derive, on a $125 \mathrm{~m}$ grid spacing, surface velocities deviating by $-5.2 \pm 4.5 \mathrm{~m} \mathrm{a}^{-1}$ from 37 on-site global navigation satellite systems-derived velocities. We find no evidence for ice flow changes on decadal time scales and we show that ice on the pinning point virtually stagnates, deviating the ice stream and causing enhanced horizontal shearing upstream. Using the BISICLES ice-flow model, we invert for basal friction and ice rigidity with three input scenarios of ice velocity and geometry. We show that inversion results are the most sensitive to the presence/absence of the pinning point in the bathymetry; surface velocities at the pinning point are of secondary importance. Undersampling of pinning points results in erroneous ice-shelf properties in models initialised by control methods. This may impact prognostic modelling for ice-sheet evolution in the case of unpinning.
\end{abstract}

KEYWORDS: ice rheology, ice shelves, ice velocity, ice-sheet modelling, remote sensing

\section{INTRODUCTION}

Almost three quarters of the Antarctic grounded ice is discharged into floating ice shelves (Bindschadler and others, 2011). Thinning of ice shelves, as observed by Paolo and others (2015), imprints the current mass loss by reducing the restraint (i.e. buttressing), which the ice shelves exert on the inland flow, subsequently causing acceleration of tributary glaciers (Scambos and others, 2004; Dupont and Alley, 2005; Joughin and others, 2014; Mouginot and others, 2014; De Rydt and others, 2015). Ice-shelf buttressing originates from lateral friction of embayments and/or from rigid obstacles emerging from the bathymetry and attaching to the ice-shelf from below.

Localized grounded areas within ice shelves form ice rumples and ice rises (Smith, 1986; Matsuoka and others, 2015). Ice rumples, on the one hand, decelerate ice flow, but are still overrun by the ice-shelf (e.g. Schmeltz and others, 2001; Humbert and Steinhage, 2011). Ice rises, on the other hand, develop a local flow regime isolated from the surrounding ice shelf (e.g. Drews and others, 2015; references therein). Distinguishing an ice rise from an ice rumple based on the (non-)locality of the flow pattern is not always straightforward, especially for smaller features that extend over only a few square kilometres; in those cases we will use the generic term pinning point.

Because ice rises (Goldberg and others, 2009; Favier and others, 2014; Favier and Pattyn, 2015) and ice rumples (Favier and others, 2012) affect the dynamics of the grounding line and that of the upstream catchment area, it is important to better understand what role these features play in defining the buttressing strength of ice shelves.
Although small pinning points (e.g. inset; Fig. 1) are common features of ice shelves in Dronning Maud Land (e.g. Matsuoka and others, 2015), they are often not covered by airborne or ground-based radars and hence not resolved in Antarctic-wide ice thickness datasets such as Bedmap2 (Fretwell and others, 2013; Fürst and others, 2015). Moreover, their surface elevation is often erroneous since satellite-altimeters tracks are too widely spaced. Antarctic-wide ice velocity maps, on the other hand, typically show the deceleration of ice flow near pinning points, but are not necessarily trustworthy at the pinning points themselves (for instance, regrounding necessitates a specific calibration for interferometric synthetic aperture radar).

Ice thickness, surface elevation and ice velocity are the primary input variables for ice flow model initialisation. A typical approach for initialising ice flow models is to invert observed surface velocities for poorly known parameters such as basal friction and ice rigidity (e.g MacAyeal, 1993; Fürst and others, 2015). As a result, if pinning points are insufficiently resolved in the observational datasets, their impact on ice-shelf dynamics may erroneously propagate to the ice-shelf rigidity during the inversion, leading to erroneous predictions in prognostic ice sheet modelling. To address this point, we analyse a small pinning point in the Roi Baudouin Ice Shelf (RBIS), Dronning Maud Land, East Antarctica, by combining radar remote sensing and inverse modelling.

The western part of the Roi Baudouin Ice Shelf $\left(26^{\circ} \mathrm{E}\right.$ and $71^{\circ} \mathrm{S}$ ), referred to hereafter as the RBIS, extends over $8500 \mathrm{~km}^{2}$ and presents several ice-shelf channels (i.e. along-flow features 


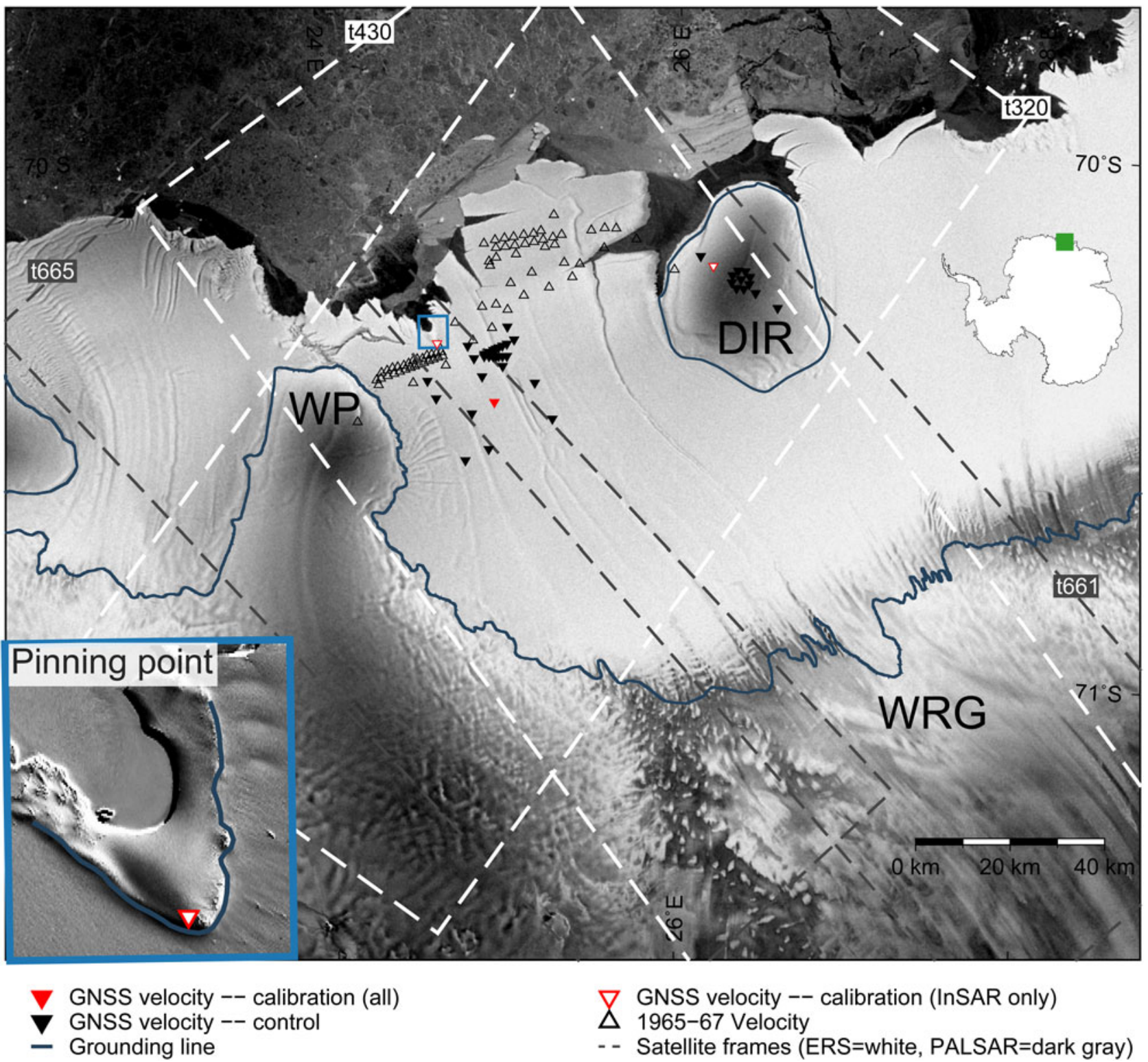

Fig. 1. Overview of the Roi Baudouin Ice Shelf (Dronning Maud Land, East Antarctica). The map locates ground-truth velocity data and the satellite scenes. WP, DIR and WRG indicate the western promontory, Derwael Ice Rise and the West Ragnhild Glacier, respectively. The blue rectangle locates the inset that displays the pinning point and the dark blue curve shows the grounding line from Bindschadler and others (2011), except in the inset where the curve designates the break in slope at the pinning point. The background images are from Radarsat mosaic (Jezek and RAMP-Product-Team, 2002) and Landsat 8 of September 2014 (inset).

of diminished thickness, expressed both at the base and at the top surface of the ice shelf). The RBIS is fed by the West Ragnhild Glacier and constrained by an ice promontory on its western side, Derwael Ice Rise towards the East, and an 8.7 $\mathrm{km}^{2}$ pinning point at the ice-shelf front (Fig. 1). This pinning point is absent in the bathymetry, ice thickness and surface elevation of Bedmap2 (Fretwell and others, 2013). The West Ragnhild Glacier drains $\sim 10 \%$ of the ice in Dronning Maud Land (13-14 Gt a ${ }^{-1}$; Callens and others, 2014) and is therefore among the major contributors to the ice discharge of Dronning Maud Land. Compared with ice shelves of other major outlet glaciers (e.g. Jutulstraulmen and Shirase Glacier), the RBIS flows more slowly (maximum speed $\approx 345 \mathrm{~m} \mathrm{a}^{-1}$ ) and ice is discharged through a comparatively wide gate at the grounding line (Callens and others, 2014).

Using interferometric synthetic aperture radar (InSAR) and speckle tracking, we first derive an ice-flow map, which is calibrated and validated with Global Navigation Satellite System (GNSS) ground-truth data (Section 2.1). We then modify the bed topography and ice thickness from Bedmap2 to account for the missing pinning point. This modified dataset is further referred to as mBedmap2. To assess the impact of the pinning point on ice flow models, we perform three inverse experiments based on three different scenarios (Section 2.2): (1) the Standard scenario using Antarctic-wide velocities (Rignot and others, 2011b) and ice thickness from Bedmap2 (Fretwell and others, 2013); (2) the Intermediate scenario combining Rignot and others (2011b)'s velocities with mBedmap2; (3) the High-resolution scenario using the high-resolution flow field derived here and in $m B e d m a p 2$. We validate and discuss our results (Sections 3 and 4) and close by drawing conclusions with respect to the role of small pinning points on ice-shelf buttressing (Section 5). 
Table 1. Characteristics of the satellite data; $\Delta T, \lambda$ and $B_{\perp}$ are the temporal baseline, the wavelength of the sensor and the perpendicular spatial baseline between the master and slave images, respectively. The satellite frames are shown in Figure 1

\begin{tabular}{|c|c|c|c|c|c|c|c|}
\hline Processing & Sensor & $\begin{array}{l}\Delta T \\
\mathrm{~d}\end{array}$ & $\begin{array}{l}\lambda \\
\mathrm{cm}\end{array}$ & Track & Date (master) & $\begin{array}{l}B_{\perp} \\
\mathrm{m}\end{array}$ & Orbit \\
\hline InSAR & ERS $1 / 2$ & 1 & 5.6 & $\begin{array}{l}320 \\
430\end{array}$ & $\begin{array}{l}21 \text { May } 1996 \\
28 \text { May } 1996\end{array}$ & $\begin{array}{l}37 \\
62\end{array}$ & $\begin{array}{l}\text { Descending } \\
\text { Ascending }\end{array}$ \\
\hline Speckle tracking & ALOS-PALSAR & 46 & 23 & $\begin{array}{l}661 \\
661 \\
661 \\
665\end{array}$ & $\begin{array}{l}1 \text { August } 2010 \\
16 \text { September } 2010 \\
1 \text { November } 2010 \\
8 \text { October } 2010\end{array}$ & $\begin{array}{l}520 \\
437 \\
453 \\
588\end{array}$ & $\begin{array}{l}\text { Ascending } \\
\text { Ascending } \\
\text { Ascending } \\
\text { Ascending }\end{array}$ \\
\hline
\end{tabular}

\section{DATA AND METHODS}

\subsection{Derivation of surface velocities}

We derived surface velocities performing InSAR and speckle tracking on data from the European Remote Sensing satellites (ERS-1 and 2 from 1996) and from the Advanced Land Observation Satellite - Phased Array type L-band synthetic aperture radar (ALOS-PALSAR from 2010), respectively. Both techniques compare two co-registered images of the same area, acquired at different times. InSAR evaluates phase differences to derive ice flow, whereas speckle tracking tracks random, but deterministic, amplitude variations. Assuming steady state, velocities were mosaicked and calibrated with ground-control points collected in 2012/13 (Fig. 1).

\subsubsection{Interferometric $S A R$ using ERS-1/2}

The individual frames of the ERS-1/2 scenes (Fig. 1; Table 1) were pre-processed to single-look complex images with Gamma's Modular SAR processor (Werner and others, 2000). Pairs with 1-day time intervals were co-registered and differenced in phase forming interferograms (Goldstein and others, 1993) with lines of constant phase-differences (a. k. a. fringes). The fringe pattern depends on the satellite orbits, surface topography and ice flow. Orbital effects were removed using the precise orbits provided by Technical University Delft (Scharroo and Visser, 1998) and the topographic contribution was cancelled using a DEM (Bamber and others, 2009). Phase differences were unwrapped using a minimum cost-flow algorithm (Costantini, 1998), transformed into a line-of-sight velocity map, and calibrated with the ground-control points marked in red in Figure 1. For the latter, the floating parts were discriminated using the dense fringe pattern caused by the tidal uplift in the grounding zone (e.g. Goldstein and others, 1993; Gray and others, 2002; Fricker and others, 2009; Rignot and others, 2011a). Calibration on the floating areas presupposes only vertical movement by tides (i.e. without tilting).

\subsubsection{Speckle tracking using ALOS-PALSAR}

Because the available InSAR data do not entirely cover the RBIS, we also used speckle tracking (Strozzi and others, 2002; Luckman and others, 2003; Werner and others, 2005) on ALOS-PALSAR images of 2010 (Fig. 1; Table 1). Each pair of PALSAR images was treated separately to generate independent flow fields. Co-registration was done solely on Derwael Ice Rise, the western promontory and the pinning point because ice flow in those areas is $<15 \mathrm{~m} \mathrm{a}^{-1}$ (Drews, 2015; Drews and others, 2015), leading to a negligible displacement of the ice-sheet surface in the 46day interval of the PALSAR images.

Offsets caused by ice flow were tracked every 12 and 36 pixels in range and azimuth, using a normalised cross-correlation of image patches $(64 \times 192$ pixels $)$, with a signal-tonoise-ratio threshold of 7 and an over-sampling factor of 2 (cf. Rankl and others, 2014). Range and azimuth offsets were georeferenced and converted to horizontal velocity fields with $125 \mathrm{~m}$ spacing. Mismatched pixels were removed (following Mouginot and others, 2012) and the flow fields were finally smoothed by averaging within $9 \times 9$ diamond-shaped windows. Because speckle tracking is insensitive to tides, only one of the InSAR ground-control points was used for the entire area (filled red triangle; Fig. 1).

\subsubsection{Mosaicking}

The four PALSAR flow fields (Table 1) were mosaicked and then blended with the ERS velocities. To reduce cutting edges, velocity maps were feathered by applying a linear taper ranging from 0 to 1 in the overlapping areas. Data gaps on the western promontory and Derwael Ice Rise were filled with Rignot and others $(2011 \mathrm{~b})$ 's flow field and feathered over $4.5 \mathrm{~km}$.

\subsubsection{On-site ice-flow measurements}

To measure ice flow, $3 \mathrm{~m}$ long markers were placed on the ice-shelf and revisited the next year (Fig. 1). The 42 stakes were positioned using geodetic, dual-phase GNSS receivers with an antenna mounted on top of the stakes, measuring for at least $30 \mathrm{~min}$. The data were post-processed using Precise Point Positioning (PPP) from the Canadian Spatial Reference System. Measurements were collected over a 3 a period. The wider-spaced markers (average distance $5 \mathrm{~km}$ ) were measured in 2012/13, and a denser network crossing an ice-shelf channel (defined in Section 1) was measured in 2013/14 (Drews, 2015). In 2012/13 some markers were tilted, leading to a maximum uncertainty of $\sim 2 \mathrm{~m}$ in the horizontal position. This error is larger than the uncertainty acquainted with the PPP, which is typically within $\mathrm{cm}$ (Kouba and Héroux, 2001). Because the average ice velocity in this area is $\sim 265 \mathrm{~m} \mathrm{a}^{-1}$, this error is $<1 \%$. We used the GNSS-derived velocities to calibrate and validate the satellite-based surface velocities (Sections 2.1 and 3.1).

Another set of ice-flow measurements stems from a triangulation network of 74 stakes measured multiple times with theodolites between 1965 and 1967 (Derwael, 2014; Fig. 1). We use this set of measurements to investigate the steady state assumption (Section 4.1). 


\subsection{Numerical modelling}

Ice-sheet response to environmental conditions depends on the ice rheology and the conditions at the bed. These variables, however, are difficult to estimate experimentally and often parametrised in ice sheet and ice-shelf models. Inverse methods enable us to infer these model parameters from observed surface velocities and ice sheet thickness.

\subsubsection{Ice-flow model}

We used the adaptive mesh finite-volume ice sheet model BISICLES (http://BISICLES.Ibl.gov) (Cornford and others, 2013), which solves the Schoof-Hindmarsh approximation (L1L2) of the full-Stokes equations on an adaptive horizontal two-dimensional (2-D) grid rendered by the Chombo adaptive mesh refinement toolkit. The L1L2 solution is based on the Shallow Shelf Approximation (SSA); vertical shearing is computed from the Shallow Ice Approximation (SIA) and represented within the effective strain-rate in Glen's flow law. BISICLES compares well with the Elmer/lce ice sheet model, which solves the full Stokes set of equations. Both models yield similar results for ideal (Pattyn and others, 2013) and real-case Antarctic outlet glaciers (Favier and others, 2014), both in terms of ice dynamics and inversion.

In the BISICLES model, the ice rheology is given by Glen's flow law:

$$
\boldsymbol{S}=2 \phi \eta \dot{\varepsilon}
$$

where $\boldsymbol{S}$ is the deviatoric stress tensor; $\dot{\boldsymbol{\varepsilon}}$ is the strain-rate tensor; $\eta$ is the effective viscosity depending on the temperature field of the ice mass (updated from Pattyn, 2010) and on the effective strain rate (Wright and others (2014) and Cornford and others (2013) provide a detailed description of $\eta) ; \phi$ is a stiffening factor that can be tuned to account for effects such as ice damage and anisotropy, along with uncertainties for ice temperature. Equation (1) is the constitutive relation used by the forward model to calculate ice flow velocities from the stress-balance equations.
For the grounded part of the ice sheet, a linear friction law governs resistance to basal sliding:

$$
\tau_{\mathrm{b}}=-C u_{\mathrm{b}}
$$

where $\tau_{\mathrm{b}}$ is the basal traction, $u_{\mathrm{b}}$ is the velocity of ice at the bottom interface and $C$ is an estimate of the friction coefficient. The magnitude of $C$ depends on different factors such as subglacial hydrology, the presence of subglacial till, etc. (MacAyeal and others, 1995).

\subsubsection{Inverse method}

To solve inverse problems, BISICLES uses the control method described by Cornford and others (2015), which is comparable with those of MacAyeal (1993) and Morlighem and others (2010). A nonlinear conjugate gradient method is used to seek a minimum of the cost function /, by expressing its gradient in terms of the adjoint equations constructed from the stress-balance equations, and defined as:

$$
J=J_{\mathrm{m}}+J_{\mathrm{p}}
$$

where $J_{\mathrm{m}}$ is the misfit between observed and modelled velocities. The Tikhonov penalty function $\int_{\mathrm{p}}$ is:

$$
J_{\mathrm{p}}=\lambda_{C} J_{C}^{\mathrm{reg}}+\lambda_{\phi} J_{\phi}^{\text {reg }}
$$

where $\lambda_{C}$ and $\lambda_{\phi}$ are the Tikhonov parameters and $J_{C}^{\text {reg }}$ and $f_{\phi}^{\text {reg }}$, respectively, represent the spatial gradients of $C$ and $\phi$ integrated over the domain (Cornford and others (2015) provide the detailed formalism). A L-curve analysis (as in Fürst and others, 2015) was performed on the High-resolution scenario to calibrate $\lambda_{C}$ and $\lambda_{\phi}$, subsequently used in all the scenarios. Figure 2 presents the results of the L-curve analysis and highlights the chosen values of $\lambda_{C}=5 \times 10^{2} \mathrm{~Pa}^{-2} \mathrm{~m}^{6} \mathrm{a}^{-4}$ and $\lambda_{\phi}=5 \times 10^{9} \mathrm{~m}^{4} \mathrm{a}^{-2}$.

\subsubsection{Inverse experiments}

We inverted simultaneously the stiffening factor $(\phi)$ and the basal friction coefficient $(C)$ for the three scenarios as
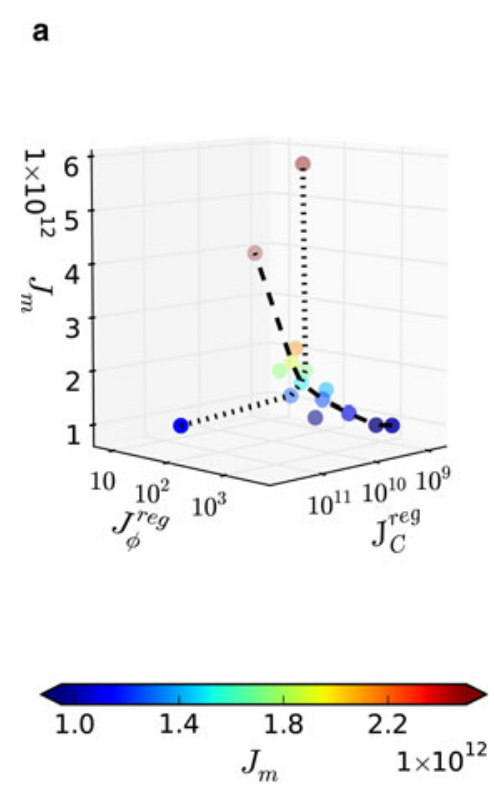
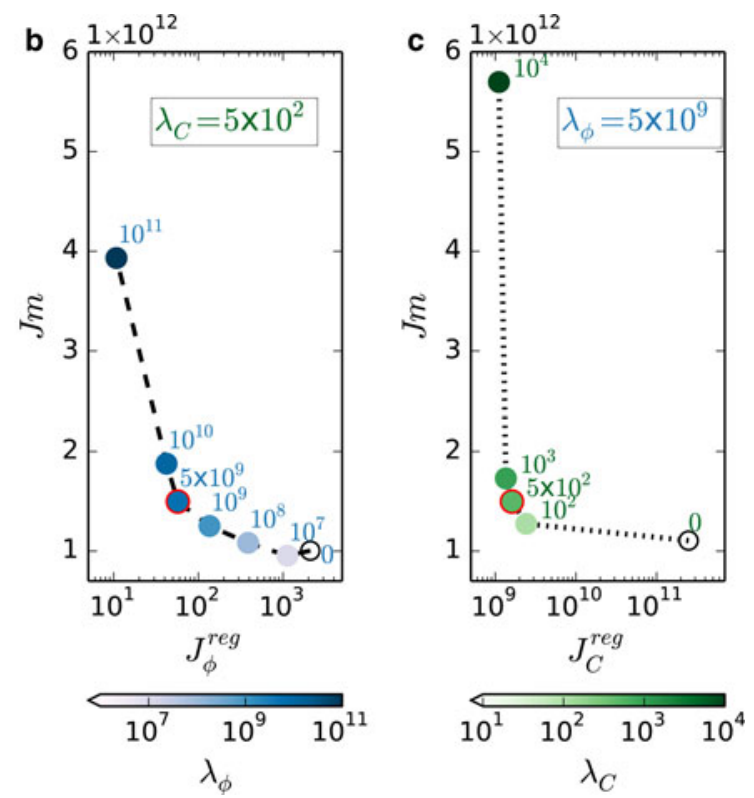

Fig. 2. L-curve analysis to select the Tikhonov parameters $\lambda_{\phi}$ and $\lambda_{C}$ : (a) 3 -D scatter plot of the model-data misfit $J_{\mathrm{m}}$ as a function of the regularisation terms $J_{C}^{\text {reg }}$ and $J_{\phi}^{\text {reg }}$. (b) 2 -D cross section for variable $\lambda_{\phi}$ and $\lambda_{C}$ fixed to $5 \times 10^{2} \mathrm{~Pa}^{-2} \mathrm{~m}^{6} \mathrm{a}^{-4}$. (c) Reverse case where $\lambda_{\phi}$ is fixed to $5 \times 10^{9} \mathrm{~m}^{4} \mathrm{a}^{-2}$ and $\lambda_{C}$ varies. The units of $J_{\mathrm{m}}$ and $J_{\mathrm{C}}^{\text {reg }}$ are $\mathrm{m}^{4} \mathrm{a}^{-2}$ and $\mathrm{Pa}^{2} \mathrm{~m}^{-2} \mathrm{a}^{2}$, respectively. $J_{\phi}^{\text {reg }}$ has no unit. 
described in Section 1. For the mBedmap2 dataset, used in the Intermediate and High-resolution scenarios, we modified the surface elevation and bathymetry of Bedmap2 by incorporating a pinning point with a Gaussian shape, with dimensions based on radar and GNSS profiles crossing the observed pinning point on the RBIS (Drews, 2015). Figure 4a shows the modifications for an along-flow cross section. We imposed a stress-free upper surface, water pressure at the calving front and the observed surface velocities at the other lateral boundaries. On the considered domain, all the inversions were performed at a $1 \mathrm{~km}$ spatial gridding.

\subsubsection{Sensitivity of the inversion to the initial guesses}

The inverse method is sensitive to the initial guesses of $\phi$ and $C$. To dampen this sensitivity, we chose physically justified initial fields for $C$ and $\phi$, called hereafter basis fields. The basis initial friction coefficient was computed from the SIA assuming balance between the driving stress and the basal friction. The basis initial stiffening factor was 1 .

The former assumption is valid for most of the Antarctic ice sheet (Morlighem and others, 2014), but may not be applicable for ice streams where basal friction is low. We addressed this uncertainty by multiplying the SIA-based friction by $0.6,0.8$ and 1.2 . As the inversion was robust under those different fields $(<1 \%$ change of the RMS difference for the observed and modelled velocities), the model was initialised with the SIA-based friction fields.

The basis initial stiffening factor of 1 corresponds to an icecreep parameter from Pattyn's (2010) updated temperatures only. In the ice sheet, no strong simplifications were applied (apart from neglecting horizontal diffusion) to calculate those temperatures, so we assumed they have sufficient physical meaning to be kept as initial conditions. However, in the ice-shelf, the temperature calculation neglected horizontal advection and internal strain heating, according to the analytical solution due to Holland and Jenkins (1999), so we investigated the sensitivity to an initial stiffening factor on the ice-shelf, ranging from 0.6 to 1.4. Increasing the initial value of $\phi$ decreased the velocity misfits ( $\sim 20 \%$ difference between 0.6 and 1.4), and stiffened the ice shelf. Ice shelves are generally stiffer than an isotropic reference, because of their strain-induced anisotropy (Ma and others, 2010). However, since the corresponding results are quantitatively almost similar and did not give qualitative differences with the highest values of the initial $\phi$, we chose to initialise the stiffening factor to 1 for the ice shelf.

\section{RESULTS}

\subsection{Satellite-derived velocities on the RBIS and strain rates}

Velocities in Figure 3a show how Derwael Ice Rise and the pinning point form a flux gate through which most of the ice of the RBIS is directed. Ice-shelf velocities average 205 $\mathrm{m} \mathrm{a}^{-1}$ and reach $345 \mathrm{~m} \mathrm{a}^{-1}$ at the front. Velocities decrease down to $0.5 \mathrm{~m} \mathrm{a}^{-1}$ on the pinning point, which is comparable with the flow velocities near the ice divides of Derwael Ice Rise and the Western Promontory.

The flow field deviates by $-5.2 \pm 4.5 \mathrm{~m} \mathrm{a}^{-1}$ and $7.5 \pm$ $16.5 \mathrm{~m} \mathrm{a}^{-1}$ from the GNSS-derived velocities and Derwael's (2014) triangulation network of 1965-67, respectively. The deviations for both ground-truth datasets do not show any spatial trend. Differences between the ERS and PALSAR mosaics decrease more or less linearly from positive values $\left(\sim 25 \mathrm{~m} \mathrm{a}^{-1}\right)$ in the northern part of the overlapping area to negative values $\left(\sim-25 \mathrm{~m} \mathrm{a}^{-1}\right)$ in the southernmost parts. Mean \pm standard deviation of the difference field is $-5.6 \pm 12.9 \mathrm{~m} \mathrm{a}^{-1}$. This systematic error likely reflects uncertainties in the baseline estimation of the ERS satellites and/or a systematic phase residual from SAR focusing (Drews and others, 2009). Strain rates were computed for a local coordinate system aligned with the main flow directions ( $y$ along- and $x$ across-flow). Horizontal shear-strain rates reveal a number of features (Fig. 3b), which are discussed in Section 4.2.

\subsection{Inversion results}

The three inversion schemes all adequately reproduce the observed velocities: the RMSD between the modelled and observed velocities are 11.51, 11.25 and $12.33 \mathrm{~m} \mathrm{a}^{-1}$ for the Standard, Intermediate and High-resolution scenarios
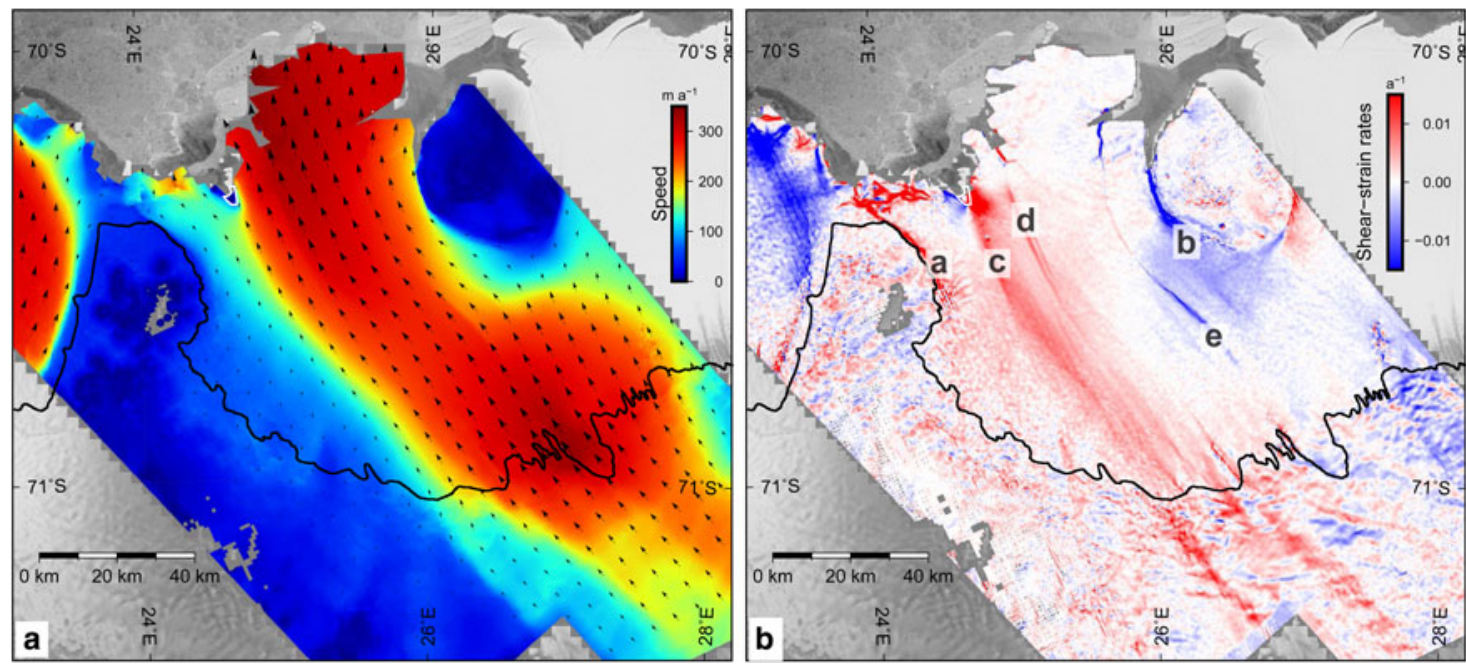

Fig. 3. (a) Horizontal surface velocities and (b) associated shear-strain rates. The grounding line (Bindschadler and others, 2011) is overlaid in black and the pinning point is marked in white. The labels a-e locate the areas of interest discussed in the text. The background image is from Radarsat mosaic (Jezek and RAMP-Product-Team, 2002). 

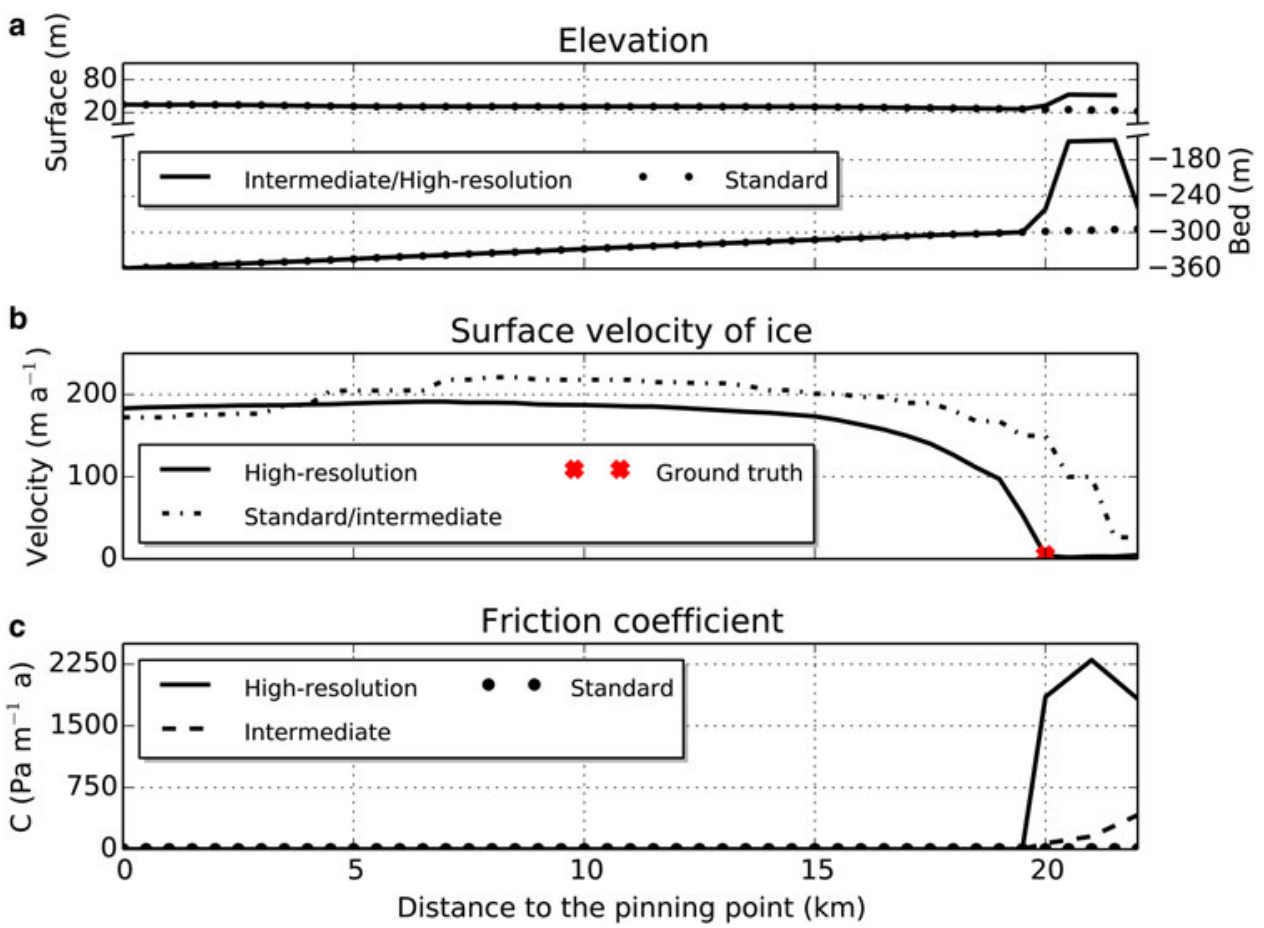

Fig. 4. Profiles along the straight line shown in Figure 5b, $d$ and f. (a) Bed and surface elevations relative to the EIGEN-GL04 geoid. (b) Comparison of the high-resolution flow field and velocities from Rignot and others (2011b). The red cross shows the ground-truth velocity measured on the pinning point. (c) Inverted friction coefficient.

on the whole domain and fall to $8.48,8.22$ and $6.38 \mathrm{~m} \mathrm{a}^{-1}$, respectively, on the ice-shelf.

Excluding the vicinity of the pinning point, the inverted basal friction displays the same general pattern for the three scenarios (Fig. 5b, d and f). The slowly flowing western promontory and Derwael Ice Rise are sticky at the bed ( $\mathrm{C}$ peaks at around 6200 and $5900 \mathrm{~Pa} \mathrm{~m}^{-1} \mathrm{a}$, respectively), whereas the fastest trunk of the West Ragnhild Glacier, upstream of the grounding line, is slippery with a basal friction coefficient ten times lower. The Standard, Intermediate, and High-resolution scenarios differ at the pinning point (insets in Fig. 5b, $d$ and f). Because the pinning point is absent from the Standard scenario (Fig. 4a), the corresponding area is frictionless. In the Intermediate experiment, the pinning point is more slippery (mean $C \approx 485 \mathrm{~Pa} \mathrm{~m}^{-1} \mathrm{a}$, for the pinning point) than the bed beneath the main stream of West Ragnhild Glacier, while in the High-resolution scenario it is on average 3.5 times stickier (mean $C \approx 1700 \mathrm{~Pa} \mathrm{~m}^{-1} \mathrm{a}$, for the pinning point) than in the Intermediate scenario.

All the experiments display four similar features in the stiffening factor $\phi$ (labelled 1-4 in Fig. 5a, c and e). Two wide patches of stiffened ice appear in the centre of the iceshelf: one, a few $\mathrm{km}$ downstream of the grounding line (label 1 in Fig. 5; $\max (\phi) \simeq 2.50$ ) and the other, dozens of kilometres upstream of the calving front (label $4-\max (\phi)$ $\simeq 2.50$ ). The most softened ice appears directly upstream of Derwael Ice Rise (label $2-\min (\phi) \simeq 0.14$ ) and, to a lesser extent, upstream of the pinning point (label 3 - min $(\phi) \simeq 0.40$ ), in its shear band (Fig. 3b; label c). The Standard experiment stands out from the Intermediate and High-resolution cases and exhibits another patch with the most stiffened ice (label $5-\max (\phi) \approx 2.75$ ). Compared with the Standard scenario, the ice-shelf is, on average, 4.0 and $4.6 \%$ softer in the Intermediate and High-resolution simulations, respectively.

\section{DISCUSSION}

\subsection{Is the Roi Baudouin Ice Shelf in steady state?}

We mosaicked two different flow fields (1996 and 2010), both of which were calibrated on the ice-shelf with the same ground-control point collected in 2012/13 (Section 2.1). This approach holds if the RBIS is in steady state. To validate this hypothesis, we compared the mosaicked flow field with 74 ground-truth measurements collected in 1965-67 (Derwael, 2014; Section 2.1; Fig. 1). The deviations are not larger than the uncertainty of our high-resolution flow field and we conclude that the RBIS has not undergone prominent changes in average ice flow over the last five decades. This justifies our steady-state assumption in Section 2.1.

\subsection{Velocities and strain rates}

Our flow field (Fig. 3a) shows that ice virtually stagnates on the pinning point with a flow regime resembling more an ice rise than that of an ice rumple. This implies that the pinning point is stickier than what is suggested by the Antarctic-wide velocities $\left(\sim 150 \mathrm{~m} \mathrm{a}^{-1}\right.$ vs. $5 \mathrm{~m} \mathrm{a}^{-1}$ for the ground truth; Fig. 4b) and that size alone is an insufficient criteria to classify ice rumples. Over a distance of only $5 \mathrm{~km}$, ice from upstream is decelerated from $180 \mathrm{~m} \mathrm{a}^{-1}$ to $0.5 \mathrm{~m} \mathrm{a}^{-1}$. The horizontal shear band upstream of the pinning point (label c; Fig. 3b) separates the stagnant part on the west of the ice-shelf from the fast flowing centre and attests to the importance of buttressing on the Western part of the RBIS. Although it is difficult to discriminate the buttressing of the western promontory from the contribution of the pinning point, the alignment between the horizontal shear band and the location of the pinning point suggests a connection. Preliminary transient simulations indicate that unpinning repositions this shear band westwards for about two-thirds 


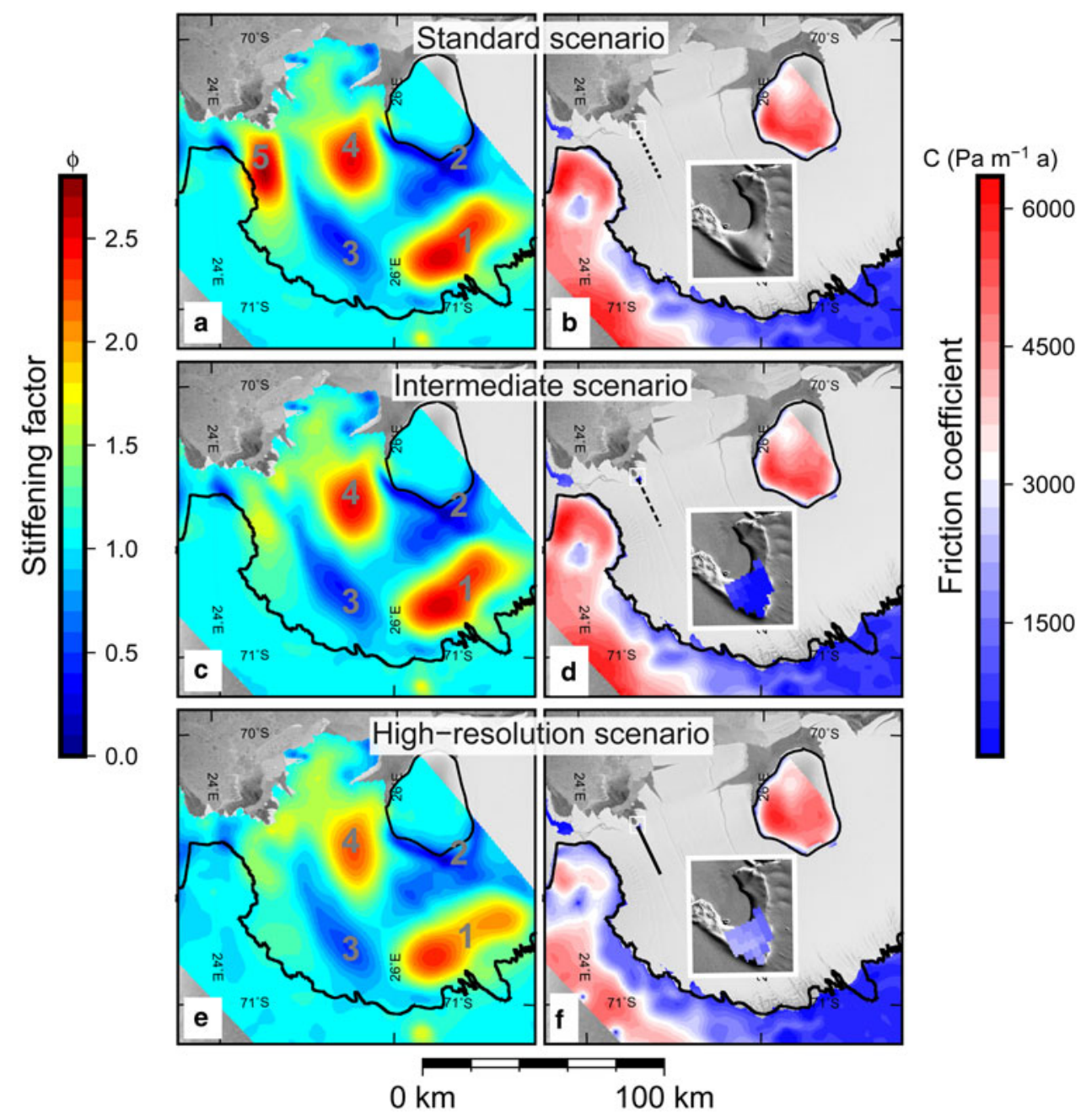

Fig. 5. (left: $\mathrm{a}, \mathrm{c}$ and e) Stiffening factor $\phi$ and (right: $\mathrm{b}, \mathrm{d}$ and f) friction coefficient $C$ inverted for the Standard (top: a and b), Intermediate (middle: c and d) and High-resolution (bottom: e and f) scenarios. The grounding line (Bindschadler and others, 2011) is overlaid in black. A profile upstream/on top of the pinning point is shown in dotted, dashed and plain lines for the Standard, Intermediate and Highresolution scenarios, respectively. Theses profiles are plotted in Figure 4. The labels 1-5 locate areas of interest. Background images are from Radarsat Mosaic (Jezek and RAMP-Product-Team, 2002) and Landsat 8 of September 2014 (inset).

of the ice shelf upstream of the pinning point. In addition to horizontal shearing at the lateral boundaries of the RBIS (labels a and b; Fig. 3b), other remarkable features of the High-resolution flow field are the enhanced velocity gradients in the vicinity of ice-shelf channels (labels $d$ and e; Fig. 3b). At the channels locations, the shearing reproduces the same pattern as that from the synthetic melting case of Drews (2015).

\subsection{Inversion for the stiffening factor and basal friction}

The High-resolution scenario has the highest averaged misfit between the observed and model velocities. However, the magnitudes of the misfits are primarily determined by the slow-flowing areas of Derwael Ice Rise and the Western Promontory, where the observations are correspondingly poor. Zooming in on the ice-shelf, the misfit of the Highresolution scenario is more than $20 \%$ lower compared with the two other scenarios.

The basal friction coefficient at the outlet of the West Ragnhild Glacier agrees with previous results (Callens and others, 2014), based on a different inversion method. Callens and others (2014) showed that the downstream part of the West Ragnhild Glacier bed is wide, flat and covered by wet sediments, which induces basal sliding, thus a low coefficient $C$. At that place, the High-resolution scenario indicates a more slippery bed because of slightly higher $(+50$ $\mathrm{m} \mathrm{a}^{-1}$ ) surface velocities between our flow field and that of Rignot and others (2011b). The sticky bed on Derwael Ice Rise and the western promontory concurs with low velocities and the negligible basal sliding in those areas.

The stiffening factor is used for fitting the modelled to the observed velocities. This means that it accounts for both physical approximations in the model and imperfections in the input data (e.g. missing factors such as damage, anisotropy and uncertainties in ice temperature); it is, however, not straightforward to distinguish between those different mechanisms. We will discuss hereafter the five patches of stiffened and softened ice (labels 1-5; Fig. 5a, c and e).

Patch 1 shows stiffened ice downstream from the grounding line, which we attribute to thermal effects. Our model uses the temperature field from Pattyn (2010), which neither accounts for horizontal advection nor horizontal shear-strain heating in the ice shelf (Holland and Jenkins, 1999). This means that the local stiffening at least partially accounts for the cold ice that is advected from the tributary glacier to the ice shelf. The softened ice in patches 2 and 3 
can be explained along the same lines, since in these areas (close to Derwael Ice Rise and upstream of the pinning point, respectively) horizontal strain heating probably occurs; moreover these areas are crevassed. The inverse model does not reveal weak margins of softer ice on the side of the ice stream, in contrast with what has been shown for faster ice shelves (e.g. Favier and others, 2014; Larour and others, 2014; Fürst and others, 2015). We have no conclusive evidence for patch 4 , and a full thermomechanical coupling will be required to draw more solid conclusions.

Patches 1-4 occur in all model runs, whereas patch 5 only appears in the Standard scenario. In this scenario, the ice slows down a few kilometres upstream of the pinning point but the latter is ignored in the bathymetry. To match the observed velocities, the inverse method must stiffen the ice in patch 5, while in the two other scenarios the inverse method can also increase the friction at the pinning point. The value of the surface velocity at the pinning point is of secondary importance : the pinning point is stickier and the ice is less stiffened in the High-resolution scenario than in the Intermediate scenario. Changing the boundary condition of the ice leads to qualitative differences, while using different velocity values only quantitatively changes the results.

Predictive simulations of the Antarctic ice sheet generally determine initial state and parameters by inverting observational data. Therefore, unresolved pinning points in the latter can result in spurious ice dynamics for transient simulations of unpinning. In the case of the Standard scenario, for example, the unpinned RBIS is erroneously buttressed by the stiff ice around the pinning point. This is not the case for the other two scenarios, i.e. softer ice near the pinning point presumably leads to higher flow velocities in unpinning experiments. Our results show that it is more important to incorporate the pinning point in the bathymetry than to resolve the velocities at the pinning point (and correspondingly the inverted basal friction coefficient), even though both may influence transient simulations of the RBIS.

Pinning points such as that presented here are features small enough to be neglected/undersampled in observational datasets but important enough to impact the ice dynamics of their surroundings. Few kilometres-wide features can have largerscale implications, although the gridding of Antarctic-wide datasets is too coarse to capture them in a modelling framework. For instance, the pinning point of the RBIS only extends over $\sim 8$ pixels when the spacing is $1 \mathrm{~km}$ (vs. 458 with $125 \mathrm{~m}$ ) and can thus easily be missed out. The results derived here accord with the findings of Durand and others (2011), demonstrating that it is important to better resolve pinning points in the bathymetry around the Antarctic coastline.

\section{CONCLUSION}

We derived a flow field for the Roi Baudouin Ice Shelf, combining satellite-based InSAR and speckle tracking techniques. The velocities deviate by $-5.2 \pm 4.5 \mathrm{~m} \mathrm{a}^{-1}$ compared with a set of 37 independent ground-control points. Comparison of our flow field with ground-truth measurements collected in 1965-67 provides no evidence for ice flow changes on decadal time scales. With its $125 \mathrm{~m}$ gridding, the derived flow field currently has the highest resolution available for the RBIS and shows that ice on top of a $8.7 \mathrm{~km}^{2}$ pinning point is virtually stagnant, contrary to what is indicated in other datasets. Despite its small size, this feature corresponds to a shear zone across the entire ice shelf.
Using different input scenarios of ice geometries/velocities we inverted for the stiffening factor (determining the ice rheology) and for the basal friction coefficient (determining the basal drag) using the BISICLES model. Surface velocities were adequately reproduced in all scenarios even in the one where the pinning point was omitted. However, including the pinning point in the bathymetry/ice thickness led to the best results on the ice shelf. The inversion for both ice rheology and basal conditions is the most sensitive to presence/ absence of the pinning point in ice thickness and bathymetry. Neglecting basal drag at the pinning point is compensated by stiffened ice in its surrounding and overestimating the surface velocities at the pinning point results in too low basal friction coefficients. Both effects can cause errors in transient simulations. Our results emphasize that ice-flow models require high-resolution for observational datasets (especially bed topography) in coastal areas to fully capture the role of pinning points and their impact on the buttressing strength of ice shelves.

\section{ACKNOWLEDGEMENTS}

This paper forms a contribution to the Belgian Research Programme on the Antarctic (Belgian Federal Science Policy Office), Project SD/SA/06A Constraining ice mass changes in Antarctica (IceCon) as well as the FNRS-FRFC (Fonds de la Recherche Scientifique) project IDyRA. We thank the InBev Baillet Latour Antarctica Fellowship for partially financing fieldwork and the International Polar Foundation for providing all required logistics in the field. ERS1/2 and ALOS data were provided by the European Space Agency (Project C1P.10754) and further processed with the help of Wolfgang Rack at the Gateway Antarctica, Canterbury University, New Zealand. Ms. S. Berger is supported by a FRS-FNRS (Fonds de la Recherche Scientifique) PhD fellowship. Support and development of BISICLES from S. Cornford and D. Martin is greatly appreciated. We finally wish to thank A. Khazendar and an anonymous reviewer for constructive comments on this manuscript.

\section{REFERENCES}

Bamber JL, Gomez-Dans JL and Griggs JA (2009) A new 1 km digital elevation model of the Antarctic derived from combined satellite radar and laser data Part 1: data and methods. Cryosphere, 3(1), 101-111

Bindschadler R and 17 others (2011) Getting around Antarctica: new high resolution mappings of the grounded and freely-floating boundaries of the Antarctic ice sheet created for the International Polar Year. Cryosphere, 5(3), 569-588

Callens D and 5 others (2014) Transition of flow regime along a marine-terminating outlet glacier in East Antarctica. Cryosphere, 8(3), 867-875

Cornford SL and 8 others (2013) Adaptive mesh, finite volume modeling of marine ice sheets. J. Comput. Phys., 232(1), 529-549

Cornford SL and 14 others (2015) Century-scale simulations of the response of the West Antarctic Ice Sheet to a warming climate. Cryosphere, 9(4), 1579-1600

Costantini M (1998) A novel phase unwrapping method based on network programming. IEEE Trans. Geosci. Remote Sens., 36 (3), 813-821

Derwael JJ (2014) Snow accumulation data: Princess Ragnhild Coast, Antarctica. Belgian - Netherlands Antarctic Expeditions 1964 - 1965 - 1966. Technical Report. Belgian Antarctic Archives, Brussels 
De Rydt J, Gudmundsson GH, Rott H and Bamber JL (2015) Modelling the instantaneous response of glaciers after the collapse of the Larsen B Ice Shelf. Geophys. Res. Lett., 42(13), 5355-5363

Drews R (2015) Evolution of ice-shelf channels in Antarctic ice shelves. Cryosphere, 9(3), 1169-1181

Drews R, Rack W, Wesche C and Helm V (2009) A spatially adjusted elevation model in Dronning Maud Land, Antarctica, based on differential SAR interferometry. IEEE Trans. Geosci. Remote Sens., 47(8), 2501-2509

Drews R and 5 others (2015) Evolution of Derwael Ice Rise in Dronning Maud Land, Antarctica, over the last millennia. J. Geophys. Res.: Earth Surf., 120(3), 564-579

Dupont TK and Alley RB (2005) Assessment of the importance of iceshelf buttressing to ice-sheet flow. Geophys. Res. Lett., 32, L04503

Durand G, Gagliardini O, Favier L, Zwinger T and le Meur E (2011) Impact of bedrock description on modeling ice sheet dynamics. Geophys. Res. Lett., 38(20), L20501

Favier L and Pattyn F (2015) Antarctic ice-rise formation, evolution and stability. Geophys. Res. Lett., 42(11), 4456-4463

Favier L, Gagliardini O, Durand G and Zwinger T (2012) A three-dimensional full Stokes model of the grounding line dynamics: effect of a pinning point beneath the ice shelf. Cryosphere, $\mathbf{6}$ (1), 101-112

Favier L and 8 others (2014) Retreat of Pine Island Glacier controlled by marine ice-sheet instability. Nat. Clim. Change, 4(2), 117-121

Fretwell P and 9 others (2013) Bedmap2: improved ice bed, surface and thickness datasets for Antarctica. Cryosphere, 7(1), 375-393

Fricker HA and 5 others (2009) Mapping the grounding zone of the Amery Ice Shelf, East Antarctica using InSAR, MODIS and ICESat. Antarct. Sci., 21(5), 515

Fürst JJ and 7 others (2015) Assimilation of Antarctic velocity observations provides evidence for uncharted pinning points. Cryosphere, 9(4), 1427-1443

Goldberg D, Holland DM and Schoof C (2009) Grounding line movement and ice shelf buttressing in marine ice sheets. J. Geophys. Res.: Earth Surf., 114(F4), F04026

Goldstein RM, Engelhardt H, Kamb B and Frolich RM (1993) Satellite radar interferometry for monitoring ice sheet motion: application to an Antarctic Ice Stream. Science, 262(5139), 1525-1530

Gray L and 6 others (2002) RADARSAT interferometry for Antarctic grounding-zone mapping. Ann. Glaciol., 34(1), 269-276

Holland DM and Jenkins A (1999) Modeling thermodynamic Ice Ocean interactions at the base of an Ice Shelf. J. Phys. Oceanogr., 29(8), 1787-1800

Humbert A and Steinhage D (2011) The evolution of the western rift area of the Fimbul Ice Shelf, Antarctica. Cryosphere, 5(4), 931-944

Jezek K and RAMP-Product-Team (2002) RAMP AMM-1 SAR image mosaic of Antarctica. Fairbanks, AK: Alaska Satellite Facility, in Association with the National Snow and Ice Data Center, Boulder, CO. Digital media

Joughin I, Smith BE and Medley B (2014) Marine ice sheet collapse potentially under way for the Thwaites Glacier Basin, West Antarctica. Science, 344(6185), 735-738

Kouba J and Héroux P (2001) Precise point positioning using IGS orbit and clock products. GPS Solutions, 5(2), 12-28

Larour E and 5 others (2014) Representation of sharp rifts and faults mechanics in modeling ice shelf flow dynamics: application to Brunt/Stancomb-Wills Ice Shelf, Antarctica. J. Geophys. Res.: Earth Surf., 119(9), 1918-1935

Luckman A, Murray T, Jiskoot H, Pritchard H and Strozzi T (2003) ERS SAR feature-tracking measurement of outlet glacier velocities on a regional scale in East Greenland. Ann. Glaciol., 36(1), 129-134
Ma $Y$ and 5 others (2010) Enhancement factors for grounded ice and ice shelves inferred from an anisotropic ice-flow model. J. Glaciol., 56(199), 805-812

MacAyeal DR (1993) A tutorial on the use of control methods in ice sheet modeling. J. Glaciol., 39(131), 91-98

MacAyeal DR, Bindschadler RA and Scambos TA (1995) Basal friction of ice stream E, West Antarctica. J. Glaciol., 41(138), 247-262

Matsuoka K and 19 others (2015) Antarctic ice rises and rumples: their properties and significance for ice-sheet dynamics and evolution. Earth-Sci. Rev., 150, 724-745

Morlighem M and 5 others (2010) Spatial patterns of basal drag inferred using control methods from a full-Stokes and simpler models for Pine Island Glacier, West Antarctica. Geophys. Res. Lett., $37(14)$

Morlighem M, Rignot E, Mouginot J, Seroussi H and Larour E (2014) Deeply incised submarine glacial valleys beneath the Greenland ice sheet. Nat. Geosci., 7(6), 18-22

Mouginot J, Scheuchl B and Rignot E (2012) Mapping of ice motion in Antarctica using synthetic-aperture radar data. Remote Sens., 4 (9), 2753-2767

Mouginot J, Rignot E and Scheuchl B (2014) Sustained increase in ice discharge from the Amundsen Sea Embayment, West Antarctica, from 1973 to 2013. Geophys. Res. Lett., 41(5), 1576-1584

Paolo FS, Fricker HA and Padman L (2015) Volume loss from Antarctic ice shelves is accelerating. Science, 348(6232), 327-331

Pattyn F (2010) Antarctic subglacial conditions inferred from a hybrid ice sheet/ice stream model. Earth Planet. Sci. Lett., 295 (3-4), 451-461

Pattyn F, L and 27 others 2013) Grounding-line migration in planview marine ice-sheet models: results of the ice2sea MISMIP3d intercomparison. J. Glaciol., 59(215), 410-422

Rankl M, Kienholz C and Braun M (2014) Glacier changes in the Karakoram region mapped by multimission satellite imagery. Cryosphere, 8(3), 977-989

Rignot E, Mouginot J and Scheuchl B (2011a) Antarctic grounding line mapping from differential satellite radar interferometry. Geophys. Res. Lett., 38(10)

Rignot E, Mouginot J and Scheuchl B (2011b) Ice flow of the Antarctic ice sheet. Science, 333(6048), 1427-1430

Scambos TA, Bohlander JA, Shuman CA and Skvarca P (2004) Glacier acceleration and thinning after ice shelf collapse in the Larsen B embayment, Antarctica. Geophys. Res. Lett., 31(18), L18402

Scharroo R and Visser P (1998) Precise orbit determination and gravity field improvement for the ERS satellites. J. Geophys. Res., 103(C4), 8113

Schmeltz M, Rignot E and MacAyeal DR (2001) Ephemeral grounding as a signal of ice-shelf change. J Glaciol., 47(156), 71-77

Smith AM (1986) Ice rumples on Ronne Ice Shelf Antarctica. Brit. Antarct. Surv. Bull., (72), 47-52

Strozzi T, Luckman A, Murray T, Wegmuller $U$ and Werner $\mathrm{CL}$ (2002) Glacier motion estimation using SAR offset-tracking procedures. IEEE Trans. Geosci. Remote Sens., 40(11), 2384-2391

Werner C, Wegmüller U, Strozzi T and Wiesmann A (2000) Gamma SAR and interferometric processing software. In Proc. ERS-Envisat Symposium.

Werner C, Wegmuller U, Strozzi T and Wiesmann A (2005) Precision estimation of local offsets between pairs of SAR SLCs and detected SAR images, Geoscience and Remote Sensing Symposium, 2005 In ICARSS '05. Proceedings. 2005 IEEE International, vol. 7, 4803-4805

Wright AP and 10 others (2014) Sensitivity of the Weddell Sea sector ice streams to sub-shelf melting and surface accumulation. Cryosphere, 8(6), 2119-2134 